\section{SCIENTTFIC SERIALS}

Transactions of the Norfolk and Norwich Naturalists' Society, vol, ii. part i., $1874-5 .-T h i s$ Society has now been in existence for seven years, and at present numbers r 40 members. It endeavours, we believe, faithfully to carry out one of the main objects of local societies, the study of the natural history of its district. This number of its Transactions contains the first section, Dicotyledonous, of a list of the flowering plants of Norfolk, forming the sixth instalment of the fauna and flora of the county, which the Society is publishing. Mr. John Quinton also contributes "Notes on the Meteorological Observations recorded at Norwich during 1874." A notable and excellent feature in this Society's publications is the miscellaneous notes, in which are briefly recorded new or interesting facts in the natural history of the county. There are several curious papers in this part. Mr. Amyot gives some details concerning a very old oak at Winfarthing Manor.-Mr. J. H. Gurney communicates some extracts from the notehook of the late Miss Anna Gumey of Northreps, in which she recorded noteworthy zoological occurrences in her neighbourhood, between 1820 and 1856.A reprint of a letter by Sir J. E. Smith, from vol. vii. of the Transactions of the Linnean Society, gives some interesting details concerning several Norwich botanists.--Mr. T. Southwell contributes an analysis of the documents from which the "Indications of Spring," communicated to the Royal Society by Robert Marsham, F.R.S., in 1789 , were compiled.-A list of I 39 birds observed on the Kimberley estate, by the Earl of Kimberley.-The wild cattle at Chillingham, by Mr. C. G. Barrett, an interesting account of a visit to those rare animals.

Foumal of the Franklin Insiitute, May.-The following are the principal papers in this number: "On the theory of the tension of belts," by Prof. L. G. Franck; the continuation of Mr. C. E. Emery's paper on "Compound and non-compound engines," and of Chief Engineer B. F. Isherwood's paper on "Experiments with different screws;" "On the mechanical equivalent of heat," the translation of a paper by M. Jules Violle. There is also a description of the Centennial Exhibition Buildings, with some excellent views, plans, and elevations.

Zeitschrift der Oesterreichischen Gesellschaft für Meteorologie, May 15.-The first paper describes a new kind of thermometer invented by Dr. Wollny, of Munich, for earth-temperature between 0.3 and I. 8 metres below the surface. - The next is the concluding part of Mr. Colding's article on winds. After explaining the effect of the rotation of the earth on great atmospheric currenats, he continues as follows:- - Let us consider the case of two winds, a polar and an equatorial, moving side by side in opposite directions, the polar being to the west of the other. Clearly the two will have a tendency to recede from each other, and in conse. quence there will be rarefaction at their neighbouring borders, producing a reaction in the two currents exactly counterbalancing the force due to rotation. Thus pressure diminishes from their outer towards their inner or neighbouring borders, where there must be a valley or depression of their surfaces. Since the magnitude of this valley depends upon the velocity of the winds, any slackening of velocity in one of them must allow it to break into the other by gravitation, and originate a hurricane revolving against the sun. It is the denser polar wind which generally breaks into the equatorial from a N.W. direction. Condensation of vapour follows, and then under certain conditions a hurricane. Now to take the other case-what will happen if the polar current flows on the east of the equatorial? The effect of the rotation of the earth will be a heaping up or condersation of air at their neighbouring borders, and the heavier current as before will invade the lighter from S.E., bringing rain. Here, however, there can be no hurricane, for gravitation acts dispersively, and the adjustment of level proceeds outwards instead of in wards. If it were possible for a hurricane to arise on the east side of the equatorial current, it would rotate "with the sun." The reason why all hurricanes rotate against the sun is now obvious. With these principles in mind, Mr. Colding thus illustrates the law of Dove: Let us inagine ourselves advancing in a westward direction out of a polar into an equatorial current. The wind turns gradually to E., then it changes to S. and S.W. as we enter the warm current; then we have it W., N.W., N., and finally N.E., in the polar current on the other side. Now at most stations where observations have been made, this direction of shift is the common one. Hence we are led to suppose that the atmosphere as a whole moves sometimes from $\mathrm{E}$, to W., but more commonly from. W. to $\mathrm{E}$. There is good reason for this view. If the atmosphere consisted of air only, there would be no reason for an excess of eastward movement, but the equatorial current, more than the polar, carries a large quantity of vapour, and this causes an excess of pressure from W. to $E$. Therefore, concludes the author, Dove's law is a real law of nature.

June $\mathbf{1}$.-The chief papers in this number bear the follow. ing titles :-_" "The Climate of the Lower Yenesei," "Co-efficients of Temperature of Naudet's Aneroid," "An empirical demonstration of the Motive Force of the Equatorial Oceanic Current," "Quantity of Carbonic Acid Gas in Desert Air." The last paper refers to an examination of the air of the Libyan desert, by which it appears that the quantity of carbonic acid gas contained by it is about the amount found in other open places.

Reale Istituto Lombardo, Rendiconti, t. 8, fasc. iii., iv., e v.-These parts contain the following papers:-Prof, L, Maggi and G. Cantoni, on some new experiments on heterogeneity and some consequences drawn from previous series ot experiments. - On the modification of the pupil observed in some cardialgies, by Dr. A. de Giovauni.-Researches on the mor. phogeny of alcoholic ferments, by Dr. J. Macagno.--Meteorological observations made at the Observatory of Brera, by Abate G. Capelli. - On some new parasilic fungi found by Dr. A. Cattaneo, of the Cryptogamic Laboratory, on some fruit affected by the so-called rosin disease and gangrene, by Prof. S. Garovaglio; the fungi belonged to the families of Sporocatus spharonema, Echinobotryum, and a new kind called Cattanea; and the part contains some excellent fliustrations of the species. - A note by Prof. C. Combroso on the causes of crime.--On the physiological effects of the faborandus, a shrub growing in the interior of some provinces of Northern Brazil, and whose leaves much resemble those of laurels, by Dr. Carlo Ambrosoli,- On the correction of temperature in a liquid into which the thermometer cannot be sufficiently immersed, by Prof. Rinaldo Ferrini.- On the centre of gravity in some homogeneous systerns, by Prof, G. Bardelli,-Observations of the periodical comet of Wimecke (1819, III.), by Prof. G. V. Schiaparelli, made at the Observatory of Brera.

Freiburg Naturforschende Gesellschaft. -This Society's Verhandlungen (vol. vi. Parts I.-III.) contain the following more important papers:-On the action of sulphur chloride upon aniline in the presence of carbon bisulphide, by A. Claus and W. Irrall--On the action of solids upon over-saturated solu. tions, by F. C. Henrici.-On the occurrence and some reactions of pJrol, by W. Schlebusch. - On the decomposition of grape sugar by cupric oxide in alkaline solution, by A. Claus,-Un some volcanic rocks of Java (with plates), by H. Rosenbusch.On nitrophenylene, by A. Claus.-Microscopic mineralogical researches, by $H$. Fischer (second paper).-On the galvanic ignition of metal wires, by Dr. J. Mitiller.-A graphic representation of Ohm's, law; notes on melting points; both these papers by the same.--On Diiodohydrine, by A. Claus.Researches on the Lesser Lamprey (Petromyzon planery), by Dr. P. Langerhans (with plates).

The Gazzetta Chimica Italiana, fasc. iv., I875, contains the following original papers :- On the hydrate of chlorine $\mathrm{Cl}_{2}+$ $10 \mathrm{H}_{2} \mathrm{O}$, by U. Schiff.- On the action of aniline on dichlorhydrine, by the same.-On the supposed transformation of the asparagine of vegretables into an albuminoid, by M. Mercadante. - Besides the above there is a literal translation of Prof. Clerk. Maxwell's paper on the dynamic evidence of the molecular constitution of bodies, as read at the Chemical Society in February last, and a summary of the contents of other journals.

The "Annali di Chinica applicata abla Medicina" (April) contains the following papers:- On chloral-collodion, by $C$. Pavesi,- - On the action of water upon subnitrate of bismuth, by A. Ditte,-On the morphogeny of alcoholic ferments, by Dr. J. Macagno.- On the action of nitrite of amyl upon the blood corpuscles, and on the temperature of the body during the inhalation of this substance, by W. B. Woodmann.-- On the origin and propagation of disease (last paper), by Sig. Calton.-On the nature of hydrophobia, by Dr. Brunetti.

Archives des Sciences Physiques et Naturelles, No. 209, May 15.-The following are the principal original papers contained in this number :--On Anæsthetics, by Dr. J. L. Prevost. Reply to that part of M. Marc Micheli's article on the progress of botany in 1874 which concerns plant-motion, by E. Hrckel. 
-On the normal spectrum of the sun, the ultra-violet part, by M. A. Cornu, with a plate.

Nachrichten won der Königl. Gesellschaft der Wissenschaften und der $G$. A. Universität zu Göttingen (Nos. I I-16, 1875).- From these publications we note the following papers:-Researches on the magnetism of steel rods, by Dr. Carl Fromme.On the oscillations of a magnet under the resisting influence of a copper ball, by Franz Himstert.-On the determination of the specific conducting resistance of gas coal, by Ed. Riecke.-On hypereiliptical integrals, by L. Koenigsberger,-On the irregularities and fundamental numbers of plane curves of the third order with points, by Dr. Hermann Schubert. - On the symmetric functions of weight (XI.), by Prof. Faa de Bruno.-On the volcanic ashes of Turrialba (Costa Rica), by Heinr. O. Lang.On the structure of German ferns, by H. Conwentz.

Gütingen Royal Sociely of Sciences.-Nos. I to Io of this society's Nachrichten contain the following among other papers: On some cut stones (flints) hitherto unknown, by Fr. Wieseler. - On elastic after effects, by Fr. Kohlrausch. - On Asa Grey's group of Diapensiacea, by Dr. O. Drude.-On a new genus of Palma of the Arecinere group, called Grisebachia, by the same and $\mathrm{H}$. Wendland.-.- On the proof of Cauchy's theorem for complex functions, by G. Mittag-Leffler.--On the curvature of some planes, by A. Enneper.-On Rabuteau's law of the toxical effect of elements and the action of lithium, by Prof. Husemann. -On a fundamental theme of Pliicker's geometry, by Dr. A. Voss.--On the ends of sensitive nerves in the skin, by Prof. F. Merkel.-On dibromobenzoic acids, by A. Burghard.-On iodosulphotoluol, by H. Glassner.--On mononitrobenzonaphtylamijes, dinitrobenzonaphtylamide and their derivatives, by $\mathrm{P}$. Ebell.-On Fucus vesiculosus, by J. Reinke.-On the action of a weak acid upon the salt of a stronger acid, by $\mathrm{H}$. Hiibner and 11. Wiesinger.-On magnetism in steel rods, by Herr Fromme. -On the specific resistance of gas-coal, by Herr Schrader.

\section{SOCIETIES AND ACADEMIES}

\section{LONDON}

Geological Society, June 23.--Mr. John Evans, V.P.R.S., presiclent, in the chair.-Some observations on the Rev. $O$. Fisher's remarks on Mr. Mallet's theory of volcanic energy, read May 12, 1875, by Robert Mallet, F.R.S. The subject of the Rev. O. Fisher's paper has been anticipated by one from Prof. Hilgard (Geol. Univ. of Michigan) published in the American Fournal of Science (vol. vii., June I874). The pith of the Rev. $O$. Fisher's communication is to a great extent comprised in the two following sentences : $-I$. That "if crushing the rocks can induce fusion, then the cubes experimented upon ought to have been fused in the crushing?" 2. "If the work (of crushing) is equally distributed throughout, why should not the heat be so also? or if noi, what determmes the localisaion?" In his reply Mr. Mallet controverts the views of the Rev. O. Fisher by bringing them into contact with acknowledged physical laws. He shows that " crushing alone of rocky masses beneath our earth's crust may be sufficient to produce fusion. He also shows that the heat developed by crushing alone camnot be equally diffused throughout the mass crushed, but must be localised, and that the circumstances of this localisation must result in producing a local temperature far greater than that due to crushing. Lasily, he shows that after the highest temperatures have been thus reached, a still further and great exaltation of temperature must arise from detrusive friction and the movements of forcible deformation of the already crushed and heated material." He therefore expresses his conviction that "there is no physical difficulty in the conception involved in his original memoir (Phil. Trans. I873), but not there enlarged upon in detail, that the temperatures consequent upon crushing the materials of our earth's crust are sufficient locally to bring these into fusion."

On the physical conditions under which the Cambrian and Lower Silurian rocks were probably deposited over the European area, by Mr. Henry Hicks. The author indicates that the base line of the Cambrian rocks is seen everywhere in Europe to rest unconformably upon rocks supposed to be of the age of the Laurentian of Canada, and that the existence of these PreCambrian rocks indicates that large continental areas existed previous to the deposition of the Cambrian rocks. The central line of the Pre-Cambrian European continent would be shown by a line drawn from S.W. to N.E. along the south coast of the English Channel, and continued through Holland and Denmark to the Baltic. Its boundaries were mountainous; they are indicated in the north by the Pre-Cambrian ridges in Pembroke. shire, in the Hebrides and Western Highlands, and by the gneissic rocks of Norway, Sweden, and Lapland. The southern line commenced to the south of Spain, passing along Southern Europe, and terminated probably in some elevated plains in Russia. Between these chains the land formed an undulating plain, sloping gradually to the south-west, its boundary in this direction being probably a line drawn from Spain to a point beyond the British Isles, now marked by the roo-fathom line. The land here facing the Atlantic Ocean would be lowest, and would be first submerged when the slow and regular depression of the Pre-Cambrian land took place. The author points out that the evidence furnished by the Cambrian and Lower Silurian deposits of Europe is in accordance with this hypothes:s. In England they attain a thickness of 25,000 to 30,000 feet ; in Sweden not more than I,000 feet; and in Russia they are still thinner, and the earlier deposits seem to be wanting. In Bohe. mia they occupy an intermediate position as to thickness and order of deposition. The author discusses the phenomena presented by the Welsh deposits of Cambrian and Lower Silurian age, and shows that we have first conglomerates composed of pebbles of the Pre-Cambrian rocks, indicating beach conditions, then ripple-marked sandstones and shallow-water accumulations, and then, after the rather sudden occurrence of a greater depres sion, finer deposits containing the earliest organisms of this region, which he believes to have immigrated from the deep water of the ocean lying to the south-west. After this the depression was very gradual for a long period, and the deposits were generally formed in shallow water; then came a greater depression, marked by finer beds containing the second fauna; then a period of gradual subsidence, followed by a more decided depression of probably $\mathrm{x}, 000$ feet, the deposits formed in this containing the third or "Menevian" fauna. This depression enabled the water to spread over the area between the south of Prussia and Bohemia and Norway and Sweden, there being no evidence of the presence of the first and second faunas over this area. The filling up of this depression led to the deposition of the shallow-water deposits of the Lingula-Flag group, followed by another sudden depression at the commencement of the 'Tremadoc epoch, which allowed the water to spread freely over the whole European area. The author next discusses the faunas of the successive epochs, and indicates that these are also in favour of his views. He indicates the probability that the animals, which are all of marine forms, migrated into the European area from some point to the south-west, probably near the equator, where he supposes the earliest types were developed. Both the lower and higher types of invertebrates appear first in the western areas ; and the groups in each case as they first appear are those which biologists now recognise as being most nearly allied, and which may have developed from one common type. The lower invertebrates appear at a very much earlier period than the higher in all the areas. In the Welsh area the higher forms (the Gasteropods, Lamellibrancbs, and Cephalopods) come in for the first time in Lower Tremadoc rocks; and with the exception of the presence of a Gasteropod in rather lower beds in Spain, this is the earliest evidence of these higher forms having reached the European area. At this time, however, no less than five distinct faunas of lower invertebrates had already appeared; and an enormous period, indicated by the deposition of nearly I 5, 0co feet of deposits, had elapsed since the first fauna had reached this area. The author points out also that a similar encroachment of the sea and migration of animals in a northwesterly direction occurred in the North American area at about the same time, the lines indicating the European and American depressions meeting in Mid-Atlantic.

On a Bone-cave in Creswell Crags, by the Rev. J. Magens Mello. In this paper the author describes some fissures contain ing numerous bones, situated in Creswell Crags, a ravine bounded by cliffs of Lower Permian limestone on the northeastern borders of Derbyshire. These cliffs contain numerous fissures. The principal one described by the author penetrates about fifty yards into the rock, and has a wide opening, but is very narrow throughout the greater part of its length. It runs nearly north and south, and inclines slightly from west to east from the top downwards. The organic remains found in the first fissure belong to fourteen mammals at least, besides a bird and a fish. The mammalia are: Man, Lepus timidus, Gulo lus. cus, Hyana spelaa, Ursus, sp., Canis hupres, Canis vulpes, Canis lagopus, Elephas primigenius, Equis caballus, Rhinoceros ticho- 